\title{
Neck Moment Characterization of Restrained Child Occupant at Realistic Nontest Standard Higher Impact Speed of $32.2 \mathrm{~km} / \mathrm{h}$
}

\author{
S. Shasthri, ${ }^{1,2}$ V. Kausalyah, ${ }^{3}$ Qasim H. Shah, ${ }^{1}$ Kassim A. Abdullah, \\ Moumen M. Idres, ${ }^{1}$ and S. V. Wong ${ }^{4}$ \\ ${ }^{1}$ Faculty of Engineering, International Islamic University Malaysia, 50728 Kuala Lumpur, Malaysia \\ ${ }^{2}$ Faculty of Engineering, Universiti Selangor, 40000 Selangor, Malaysia \\ ${ }^{3}$ Faculty of Engineering, Universiti Teknologi Mara, 40000 Selangor, Malaysia \\ ${ }^{4}$ Malaysian Institute of Road Safety Research (MIROS), 43000 Selangor, Malaysia
}

Correspondence should be addressed to S. Shasthri; shasthri@yahoo.com

Received 9 April 2014; Accepted 30 June 2014; Published 11 September 2014

Academic Editor: Abdelaziz Bensrhair

Copyright (C) 2014 S. Shasthri et al. This is an open access article distributed under the Creative Commons Attribution License, which permits unrestricted use, distribution, and reproduction in any medium, provided the original work is properly cited.

\begin{abstract}
The effects of bullet vehicle crash impact angle, child restraint system design, and restraint harness slack at side impact speed of $32.2 \mathrm{~km} / \mathrm{h}(20 \mathrm{mph})$ on moments sustained at the neck by a three-year-old child are investigated. Mathematical models are built using the response surface method based on simulation results whereby good fitness is achieved. The singular and cross interactive effect of each predictor on the neck moment are analyzed. The number of significant parameters affecting the neck moment is shown to be the largest for wide impact angles $\left(\phi \geq 60^{\circ}\right)$ and the impact angle parameter is largely revealed to be the most sensitive. An ideal safe range for low neck moment has been established to be within $\phi$ angles $45^{\circ}$ and $65^{\circ}$. It is further shown that the nature of all parameters effect on the neck moment is highly dependent on the impact angle range.
\end{abstract}

\section{Introduction}

It has been shown over the last two decades that vehicle crashes have become the leading cause of death for children in many developed countries [1-4]. The side impact crash mode especially is shown to be a particularly harmful mode $[5,6]$. Many factors contribute to this scenario, one of which is the presence of shoulder harness slack $[3,6,7]$. Another is due to the kinematics of side impact crash which depends upon both the magnitude of the impulse from the bullet vehicle and its principle direction of force (PDOF) impacting angle [8]. In addition, it has been shown that the head contact with intruding door due to the bullet vehicle plays a pivotal role and has to be considered in addressing any mitigation efforts $[9,10]$.

Although head injuries are largely reported to be prime cause of fatalities in child restraint system (CRS) restrained toddlers involved in side impact crash $[3,4,10,11]$, there is sufficient cause for concern where the fatality may also be related to high neck loading [12]. Investigation of neck moments pertaining to CRS design, misuse, and crash parameters is yet unexplored due to insufficient accident data and costly full vehicle analysis simulations. Thus, the effects and relationships between the singular and cross interactive parameters, especially for oblique side impact involving intrusion, are not studied [10]. Insights obtained from such a work would serve to promote better understanding of the side impact crash event in order to achieve greater injury mitigation.

In this work, a study is undertaken to characterize the neck moment (NM) of a CRS restrained 3-year-old child occupant involved in lateral and oblique side impact, with respect to identified relevant crash parameters. A prescribed structural motion (PSM) simulation is carried out where a prevalidated Hybrid model consisting of both finite elements (FE) and multibodies ( $\mathrm{Mb}$ ) is subjected to a pulse, which represents the bullet vehicle kinematic impact load. The methodology allows for significant savings in computational cost while preserving the required accuracy. The commercially available MADYMO 7.4.1 by TASS is used for the 


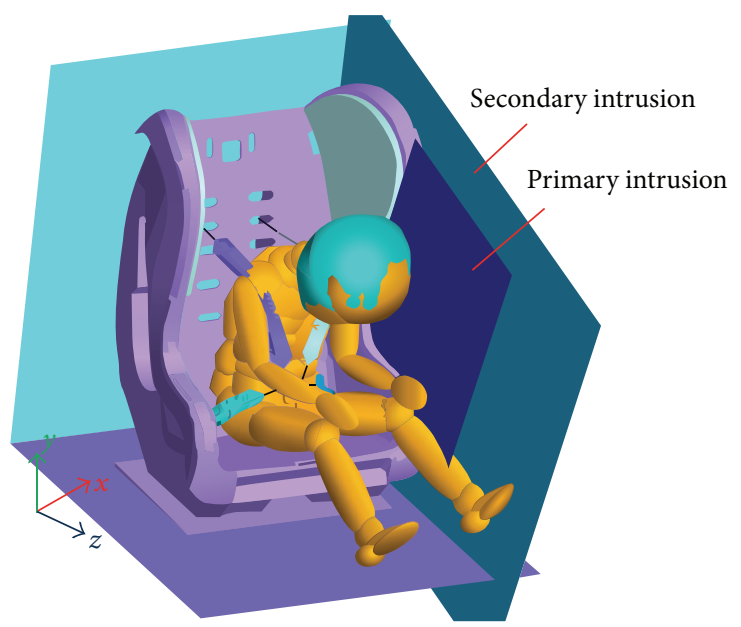

FIGURE 1: Oblique side impact PSM simulation.

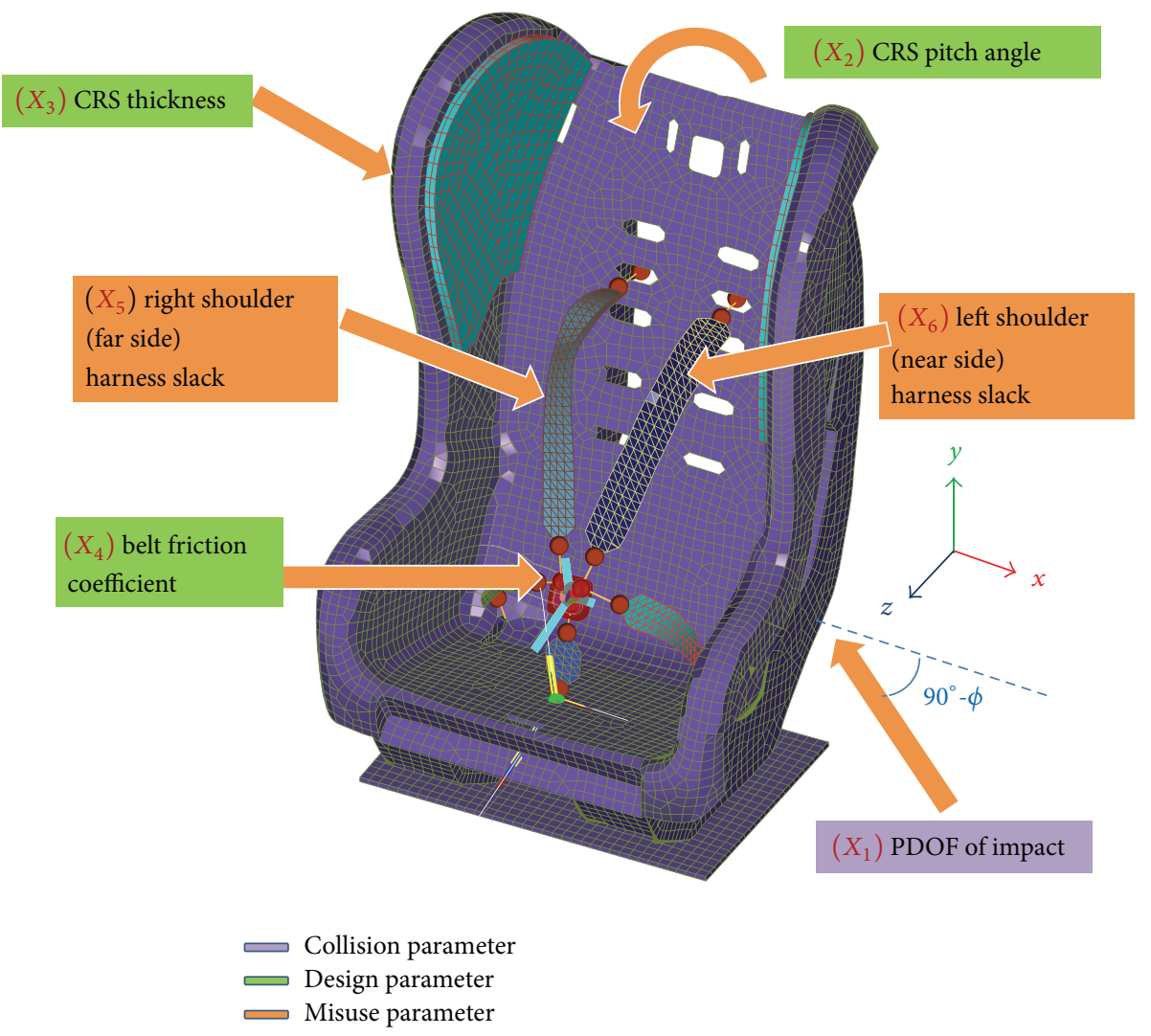

FIGURE 2: CRS parameters considered for oblique side impact.

simulation due to its capability to handle both FE and MB. A design of experiments (DoE) using the Latin hypercube sampling (LHS) is employed to build mathematical models using the response surface method (RSM). Statistical methods are used to map the parameter sensitivity upon the NM both individually and cross interactively. Statistical modelling and analysis are conducted using MATLAB 2013a. The present work reports data corresponding to a bullet vehicle impact speed of $32.2 \mathrm{~km} / \mathrm{h}$ (20 mph) based on the TRC
595 pulse which is relatively higher compared to the standard manufacturer-friendly test impact speed of $24.4 \mathrm{~km} / \mathrm{h}$ (15 mph) [13]. The selected velocity is considered to be a more realistic estimation of the crash event.

\section{Numerical Modelling}

An R44-standard compliant CRS is modelled using shell elements with a specified thickness of $4 \mathrm{~mm}$. LS-PrePost 4.1 by 


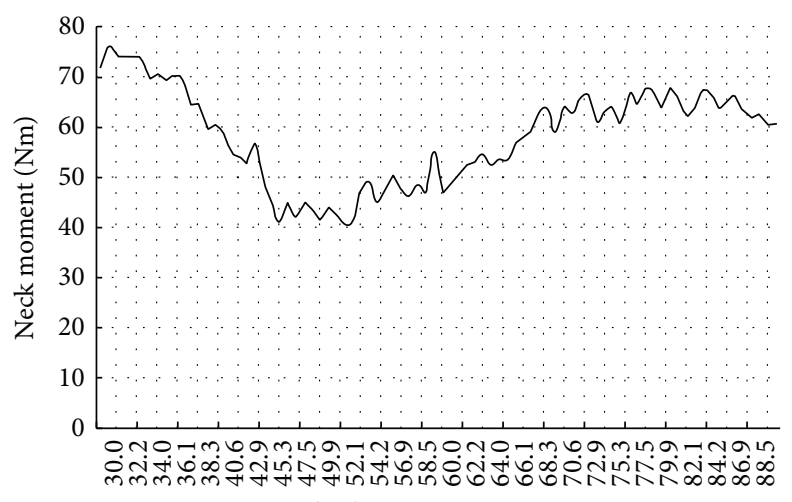

$\left(X_{1}\right)$ (PDOF $\phi$ degrees)

FIGURE 3: Effect of impact angle parameter $X_{1}$ on neck moment.

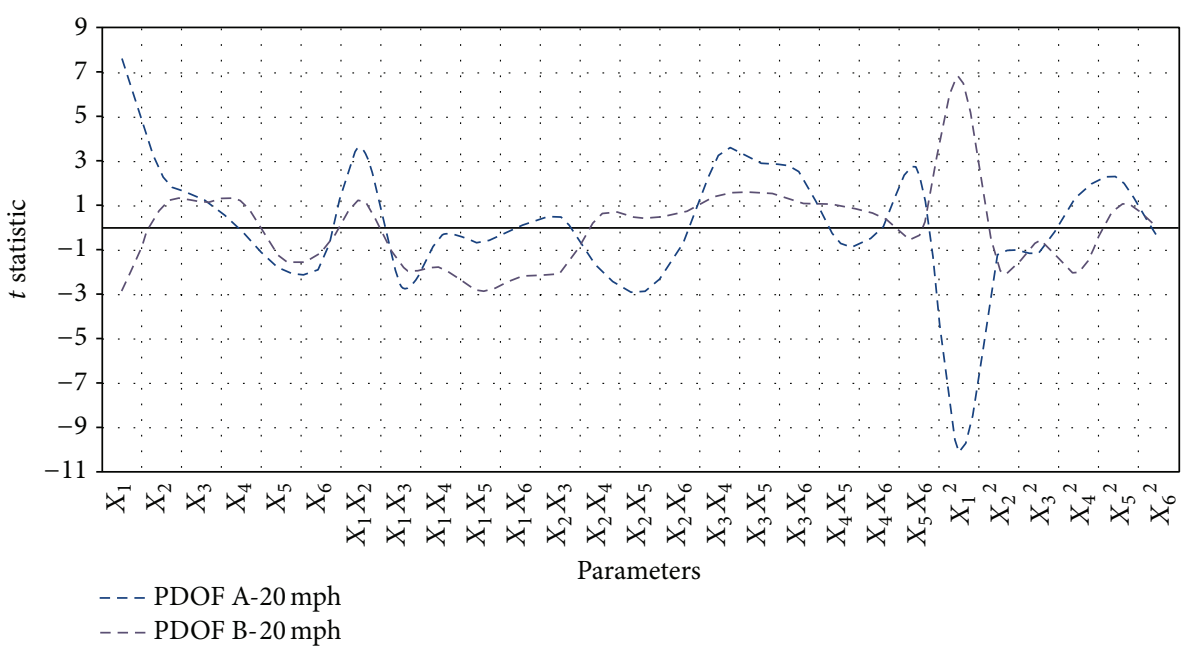

FIGURE 4: Qualitative analysis of neck moment response for RS models.

Livermore Software Technology Corporation is used for the FE model mesh generation. The material property is defined as polypropylene. The density $(\rho)$, Young's modulus $(E)$, and Poisson's ratio $(\mu)$ are specified, respectively, as $800 \mathrm{kgm}^{-3}$, $0.842 \mathrm{GPa}$, and 0.3 whereas the yield and the ultimate tensile strengths are set as $8.76 \mathrm{MPa}$ and $18.76 \mathrm{MPa}$, respectively [14-16]. A foam insert comprising solid elements is also modelled as shown in Figure 1. This is placed at the side wings of the CRS to absorb head impact. A highly compressible low-density foam material model $\left(\rho=50.2 \mathrm{kgm}^{-3}, E=\right.$ $5.463 \mathrm{MPa}$ ) is used $[7,16]$. The CRS is constrained at base anchorage points on a ECE R.44 test bench using fixed cross bars. The boundary conditions and simulations are done in MADYMO 7.4.1.

The five-point harness system of the CRS is modelled predominantly using $1 \mathrm{~mm}$ thick membrane elements ( $\rho=$ $890.6 \mathrm{kgm}^{-3}, E=2.068 \mathrm{GPa}$, and $\mu=0.3$ ). However, to reduce computation time, the FE belts are connected at both ends to the anchor point using rigid bodies. Loading and unloading data with hysteresis are provided for both belt types $[7,16,17]$. No slack is allowed for the belt fitting [14].

An intrusion of $280 \mathrm{~mm}$ is considered $[13,18]$ and this is achieved by means of introducing rigid static planar-surfaces as shown in Figure 1. The secondary intrusion plane $(130 \mathrm{~mm}$ intrusion) has contact defined against the CRS as well as the child dummy whereas for the primary intrusion plane, only the head is allowed to contact with it. This arrangement is assumed to cater for the worst case scenario of the intrusion whereby the head is free to strike the hardest part of the intruding door, at the earliest moment of time.

A commercially available ellipsoid Hybrid III 3 YO child dummy model is used in this work [17]. Both dummy and CRS are subjected to gravitational loading as well as acceleration pulse to simulate lateral side impact. Dynamic simulation time is set to terminate after $125 \mathrm{~ms}$. Convergence study is carried out during the trial runs and a good tradeoff between model cost and accuracy is achieved with an element count of 24,320 . The entire model assembly has been previously validated and it has been shown to be both accurate and 


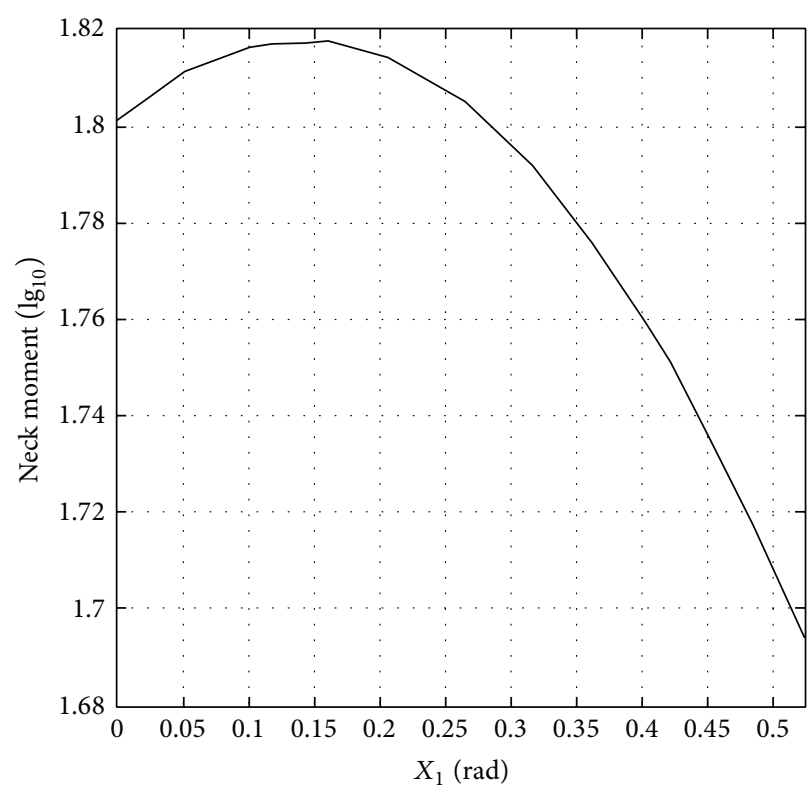

(a) NM versus $X_{1}$ for PDOF A

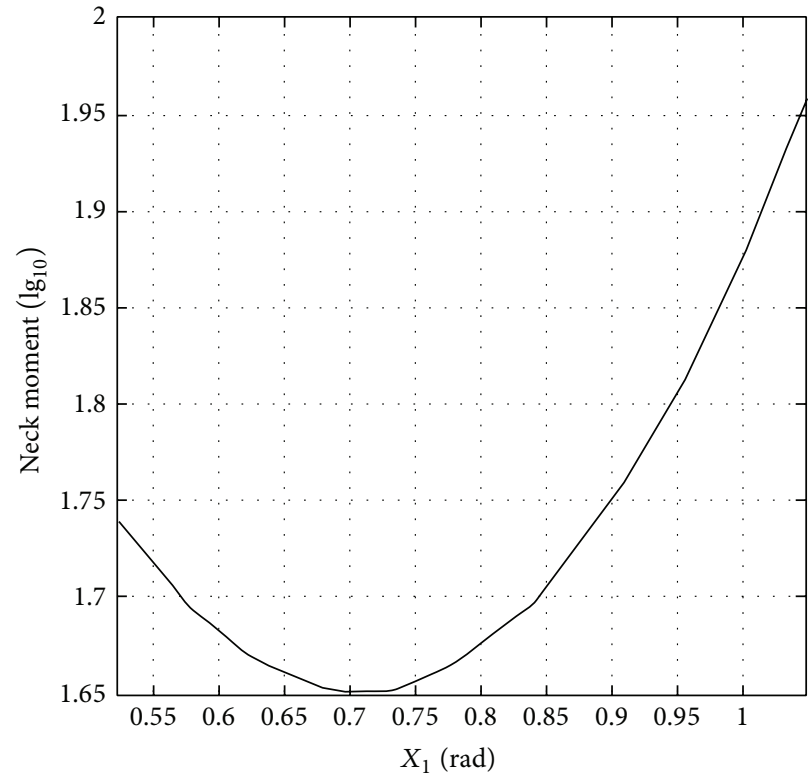

(b) NM versus $X_{1}$ for PDOF B

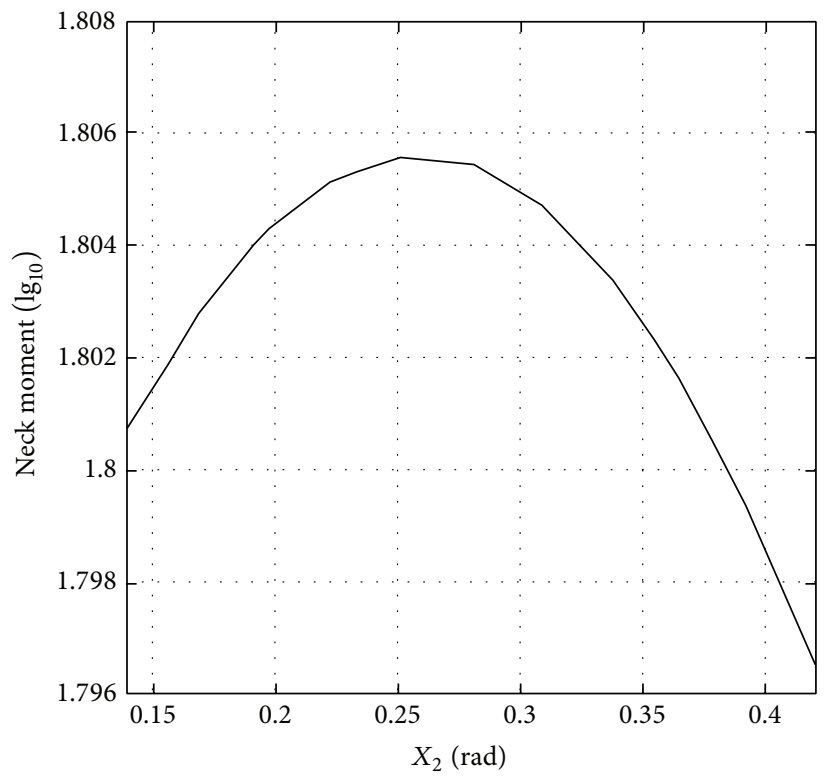

(c) NM versus $X_{2}$ for PDOF A

FIGURE 5: NM significant singular parameter response line plots.

computationally economical with each run typically taking only 20 minutes [19].

\section{Statistical Modeling}

Figure 2 illustrates the parameters selected for the sensitivity study and Table 1 shows organization of the DoE as well as the upper and lower bounds considered for each parameter adopted from standards $[20,21]$. To further increase the sensitivity of the study, the PDOF impact angle $(\phi)$ is divided into two groups, namely, PDOF A $\left(60^{\circ} \leq \phi \leq 90^{\circ}\right)$ and PDOF B $\left(30^{\circ} \leq \phi \leq 60^{\circ}\right)$. The first caters for a wide PDOF angle $\left(\phi \geq 60^{\circ}\right)$ impact approach while the latter represents a narrow impact approach $\left(\phi \leq 60^{\circ}\right)$. The ensuing NM response plots generated by MADYMO are recorded. Multinomial regression is used as a method to determine parameter sensitivity and hence a quadratic response surface method (RSM) is used to model the problem. The response data is converted to logarithmic values of base 10 and submitted for regression analysis. 


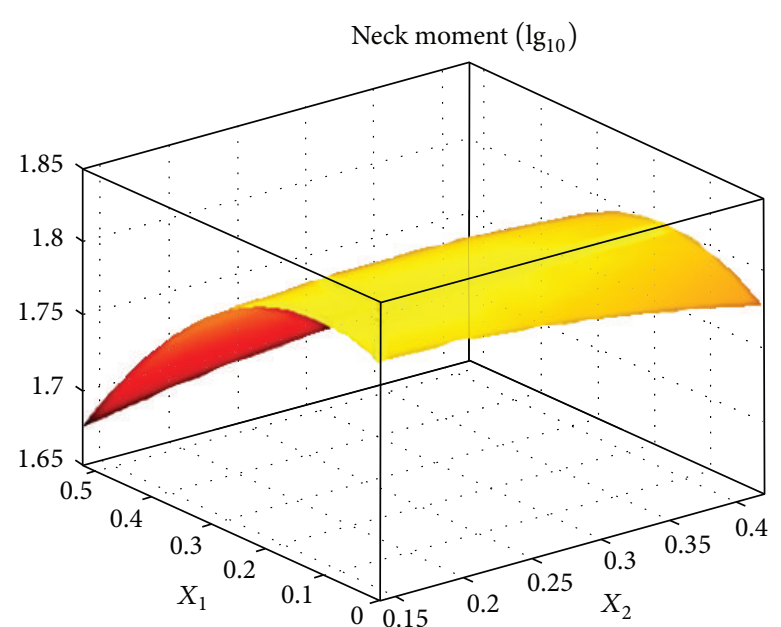

(a) $X_{1} X_{2}$ versus NM-PDOF A

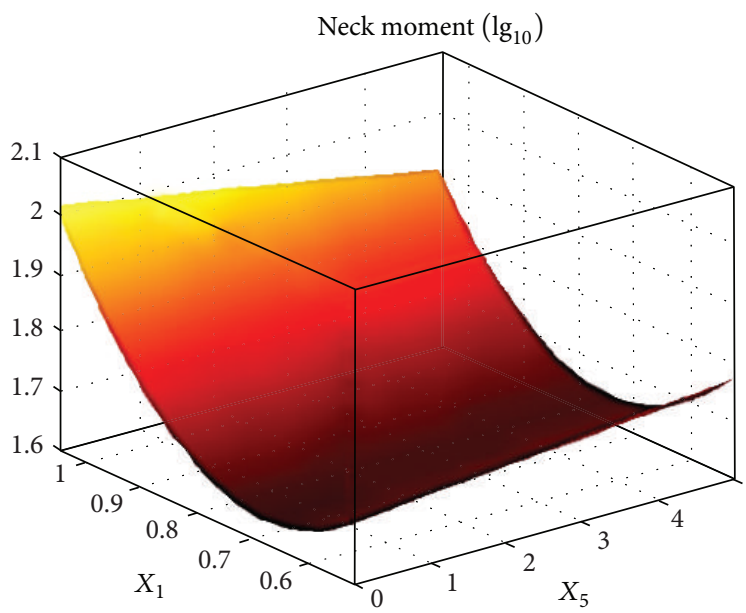

(c) $X_{1} X_{5}$ versus NM-PDOF B

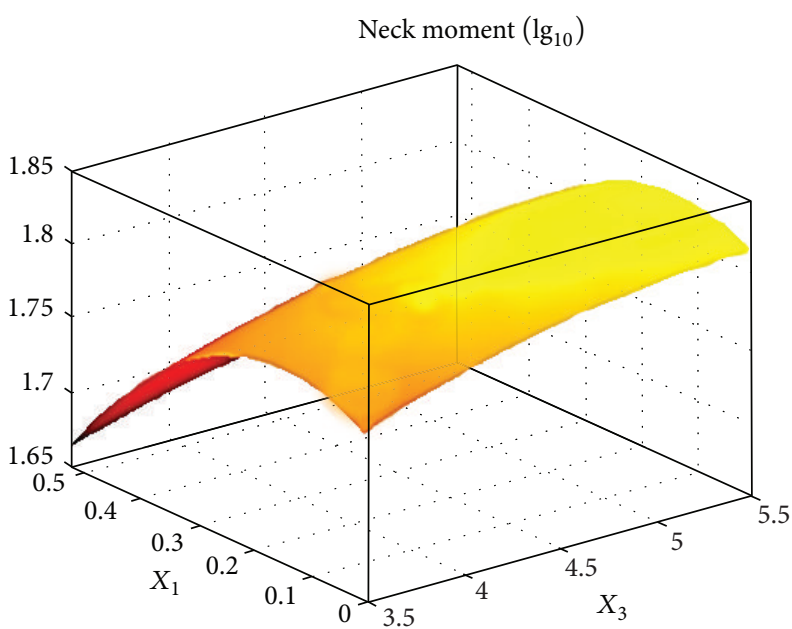

(b) $X_{1} X_{3}$ versus NM for PDOF A

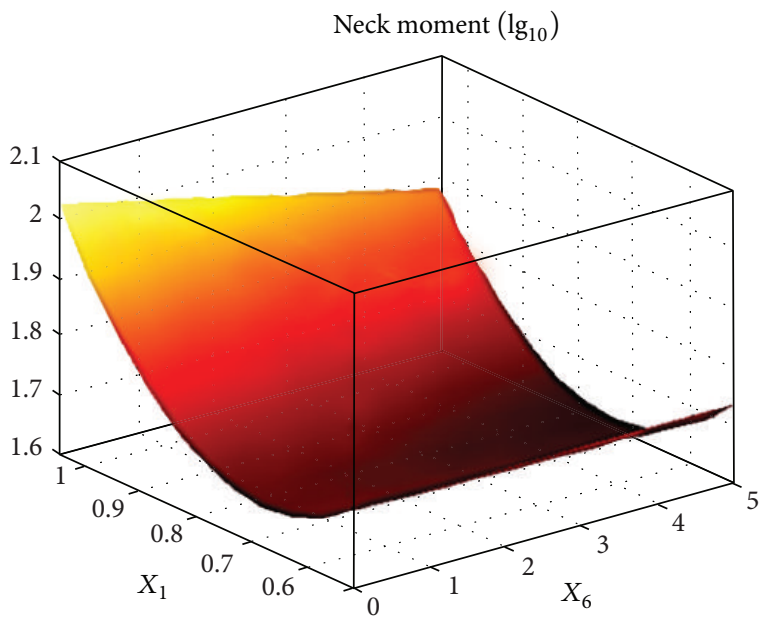

(d) $X_{1} X_{6}$ versus NM for PDOF B

FIGURE 6: NM significant $X_{1}$ cross interactive parameter response surface plots.

TABLE 1: DOE grouping and parameter bounds.

\begin{tabular}{lcc}
\hline Attributes & PDOF A & Group \\
& $0^{\circ} \leq X_{1} \leq 30^{\circ}$ & $30^{\circ} \leq X_{1} \leq 60^{\circ}$ \\
$X_{1}\left(90^{\circ}-\phi\right)$ (degrees) & $8^{\circ} \leq X_{1} \leq 24^{\circ}$ \\
$X_{2}($ degrees $)$ & $3.5 \leq X_{1} \leq 5.5$ \\
$X_{3}(\mathrm{~mm})$ & $0.25 \leq X_{1} \leq 0.35$ \\
$X_{4}($ value $)$ & $0 \leq X_{1} \leq 5$ \\
$X_{5}(\mathrm{~cm})$ & $0 \leq X_{1} \leq 5$ \\
$X_{6}(\mathrm{~cm})$ & $32.2 \mathrm{~km} / \mathrm{h}(\mathrm{TRC} 595)$ \\
Pulse & \\
\hline
\end{tabular}

\section{Results and Discussion}

From the DoE tabulations, the full range of $X_{1}$ values encompassing both PDOF $\mathrm{A}$ and $\mathrm{B}$ groups against the NM response is plotted as shown in Figure 3. The values seem to peak at $30^{\circ}$ with approximately $75 \mathrm{Nm}$. A favourable low neck moment of $50 \mathrm{Nm}$ and below seems to be indicated between PDOF $\phi$ angles $45^{\circ}$ and $62^{\circ}$. The NM severity range (approximately above $60 \mathrm{Nm}$ ) is indicated for PDOF impact angles to be less than $40^{\circ}$ and greater than $66^{\circ}$.

Table 2 shows the statistical diagnostics obtained for all four models. From the regression coefficients, good fitness is indicated for all the models where the model errors are shown to be low as given by the small RMSE values. The $R^{2}$ and $R^{2}$ adjusted ( $R^{2}$ Adj.) values substantiate this conclusion and provide a good indication of the model fitness with all values approaching unity. Additionally, results from the Fisher $(F)$ test reconfirm that the RSM models are statistically acceptable and this is supported by the low associated $P$ values.

Student's $t$-test is used to identify the major contributing single parameters and cross interaction parameters as well as assess their respective parametric significance. Figure 4 depicts the full data distribution and pattern of the $t$ statistic values for each model in graphical form while Table 3 shows the $t$ statistics for only the significant parameters identified. A quick glance reveals that the PDOF A groups obviously register more numbers of significant parameters than the 


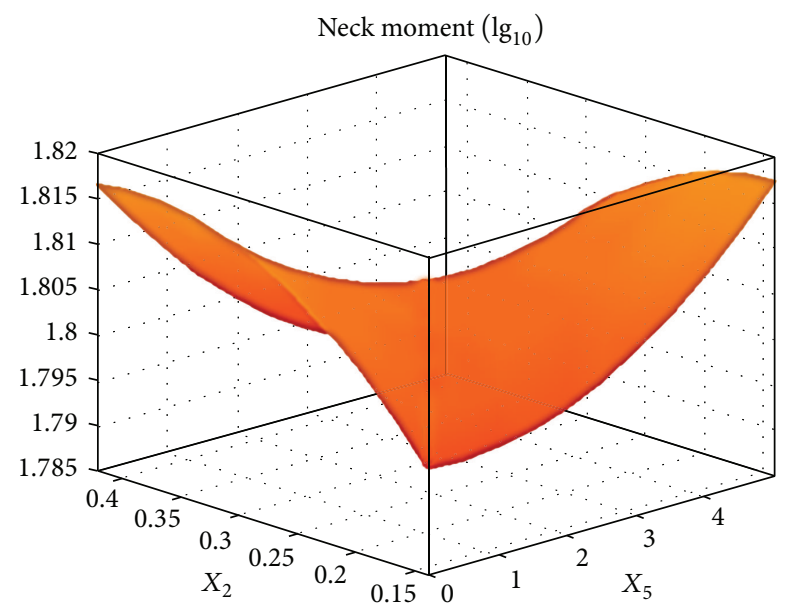

(a) $X_{2} X_{5}$ versus NM-PDOF A

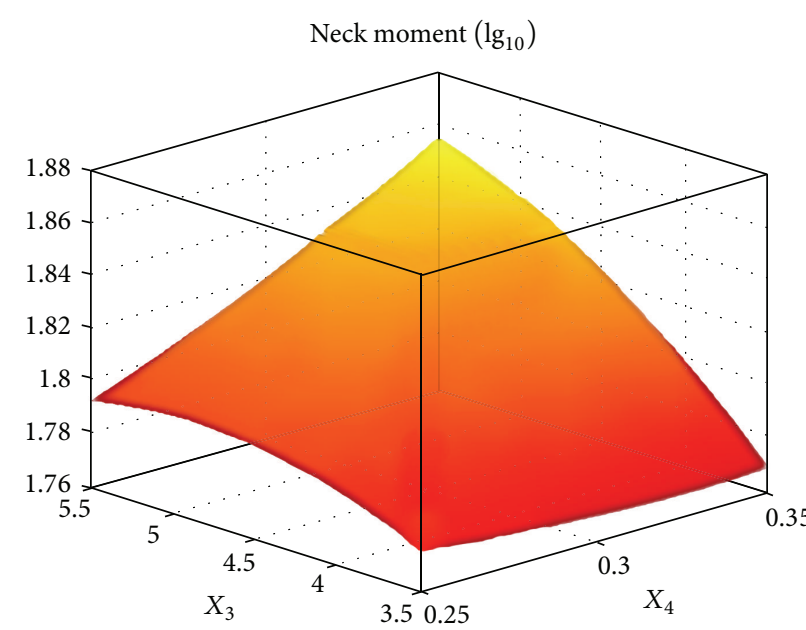

(b) $X_{3} X_{4}$ versus NM for PDOF A

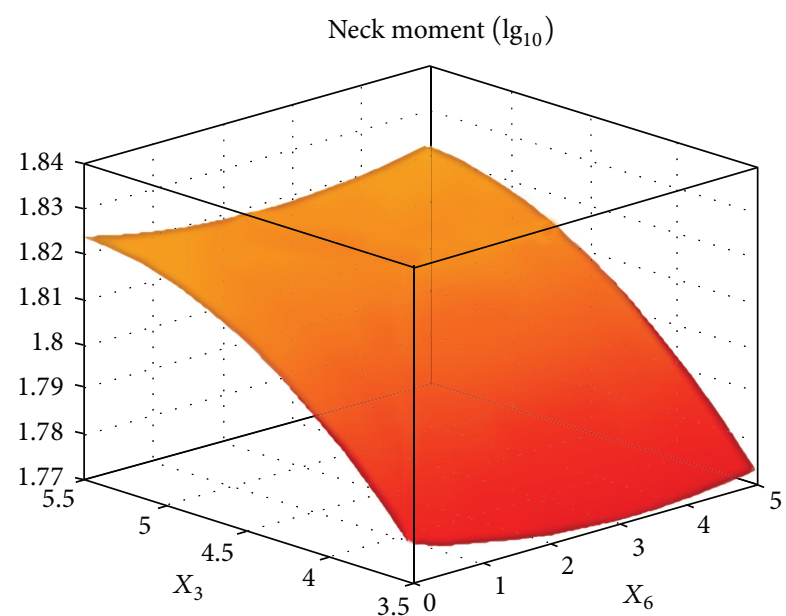

(d) $X_{3} X_{6}$ versus NM for PDOF A

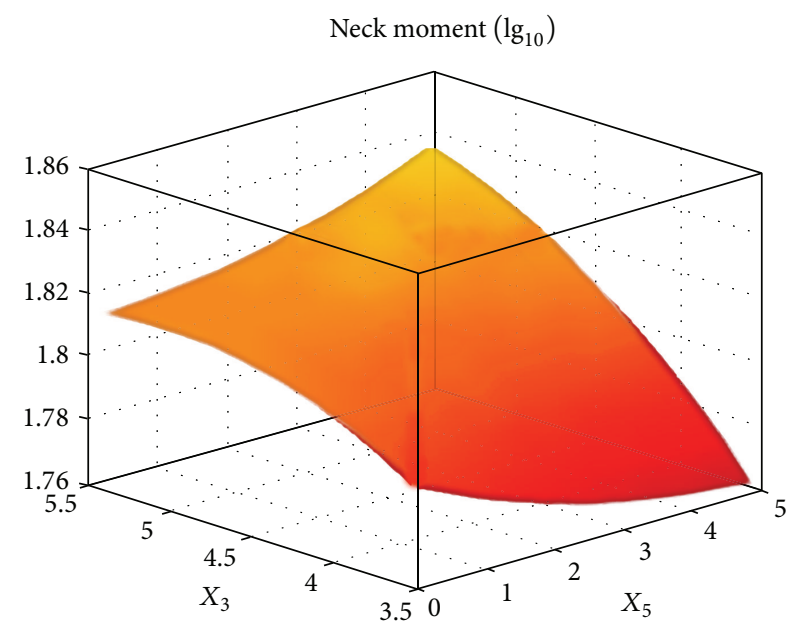

(c) $X_{3} X_{5}$ versus NM-PDOF A

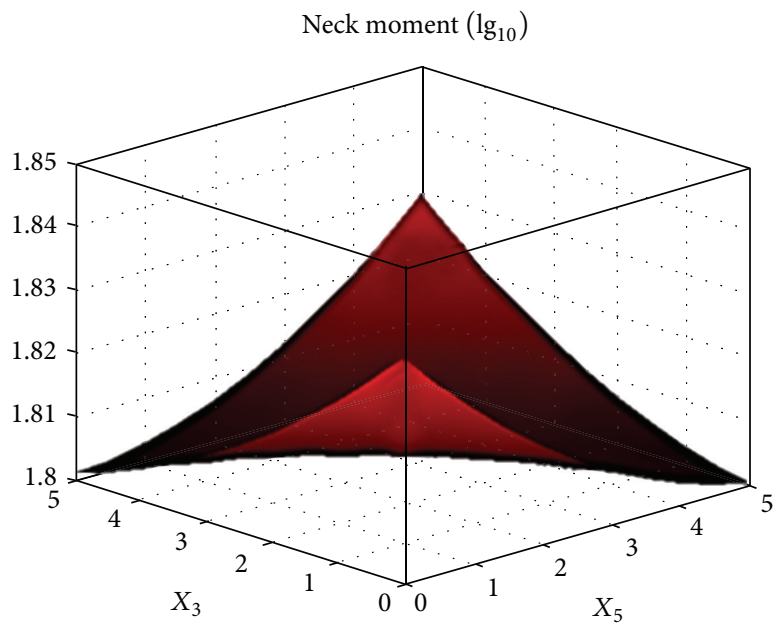

(e) $X_{5} X_{6}$ versus NM-PDOF A

FIGURE 7: NM other significant cross interactive parameter response surface plots. 
TABLE 2: Model fitness diagnostic statistics.

\begin{tabular}{|c|c|c|c|c|c|}
\hline \multirow{3}{*}{ RSM models } & \multicolumn{5}{|c|}{ Model fitness statistics } \\
\hline & \multicolumn{2}{|c|}{ Fisher test } & \multirow{2}{*}{$R^{2}$} & \multirow{2}{*}{$R^{2}$ Adj. } & \multirow{2}{*}{ RMSE } \\
\hline & $F$ statistic & $P$ value & & & \\
\hline PDOF A & 143.011 & $4.841 E-13$ & 0.9964 & 0.9894 & 0.006 \\
\hline PDOF B & 18.409 & $5.3650 E-7$ & 0.9726 & 0.9198 & 0.015 \\
\hline
\end{tabular}

Note: Only parameters having $P$ value of less than 0.05 are included in the table.

PDOF B groups. This shows that the NM of the restrained 3 -year-old child during side impact is very much affected by the designated parameters both individually and cross interactively for wide PDOF impact angles of $\phi \geq 60^{\circ}$.

A scrutiny of Table 3 and Figure 4 reveal the PDOF impact angle $\phi\left(X_{1}\right)$ to be the most sensitive parameter for all cases, both singularly and cross interactively. Singularly, the significance is found to be especially pronounced for wide PDOF impact angles $\left(\phi \geq 60^{\circ}\right)$ where the $P$ value is shown to be relatively very small $(t=7.6795, p=2.20 E-6)$. It is interesting to note that, contrary to PDOF A, values for PDOF $\mathrm{B}\left(\phi \leq 60^{\circ}\right)$ are negative indicating that increase in $X_{1}$ serves only to reduce NM. The response surface line plots for $X_{1}$ with respect to NM for both impact angle groups are shown in Figure 5.

Cross interactively, the parameters $X_{1} X_{5}$ and $X_{1} X_{6}$ register moderate significance for PDOF B although this observation is not seen to hold for wider impact angles (PDOF A). For the later impact angle group, $X_{1}$ interaction is notable with $X_{2}$ and $X_{3}$. No interaction with parameter $X_{4}$ is seen for any of the models. The response surface plots for these significant interactions with $X_{1}$ are depicted in Figure 6.

The CRS pitch angle parameter $\left(X_{2}\right)$ is found to be sensitive only for wide PDOF impact angles $\left(\phi \geq 60^{\circ}\right)$ (Figure 5(c)). Cross interactivity of the parameter with $X_{1}$ (Figure 6(a)) as well as with $X_{5}$ is observed (Figure $7(\mathrm{a})$ ). The CRS shell thickness parameter $X_{3}$ is also found to be significant only cross interactively and that too only for wide PDOF impact angles (PDOF A). Four interactions, $X_{1} X_{3}$, $X_{3} X_{4}, X_{3} X_{5}$, and $X_{3} X_{6}$, are seen of which the response surface plots for the last three are given in Figures $7(b), 7(c)$, and $7(d)$, respectively. Except for the first interaction (Figure 6(b)), the other three are shown to have a positive effect on neck moment.

The harness coefficient of friction parameter $X_{4}$ indicates the least sensitivity in this study with only a single positive cross interaction with $X_{3}$ (Figure $7(\mathrm{c})$ ) seen for PDOF A. The misuse parameter $X_{5}$ (far side harness slack) is found to be singularly insignificant for the determination of neck moment in side impact crash. However, cross interactively, three observations $\left(X_{2} X_{5}, X_{3} X_{5}\right.$, and $\left.X_{5} X_{6}\right)$ of moderate significance are noted for PDOF A. The response surface plots are given in Figures 7(a), 7(c), and 7(e), respectively. Similar to $X_{5}$, the $X_{6}$ parameter (near side harness slack) has no singular significance but retains some cross interactivity across the models. The PDOF B group has only one cross interaction parameter, $X_{1} X_{6}$ (Figure 6(a)), while PDOF A reveals two observations $X_{3} X_{6}$ (Figure $7(\mathrm{~d})$ ) and $X_{5} X_{6}$ (Figure $7(\mathrm{e})$ ), all of moderate significance.
TABle 3: Student's $t$-test and significance $P$ of parameters for NM response.

\begin{tabular}{lcccc}
\hline \multirow{2}{*}{ Significant parameters* $^{*}$ 20 PDOF A } & \multicolumn{2}{c}{20 PDOF B } \\
& $t$ & $P$ & $t$ & $P$ \\
\hline$X_{1}$ & 7.6795 & $2.20 \mathrm{E}-\mathbf{6}$ & -2.7923 & 0.0144 \\
$X_{2}$ & 2.4049 & 0.0306 & & \\
$X_{1} X_{2}$ & 3.6455 & $\mathbf{0 . 0 0 2 6}$ & & \\
$X_{1} X_{3}$ & -2.5905 & 0.0214 & & \\
$X_{1} X_{5}$ & & & -2.8355 & 0.0132 \\
$X_{1} X_{6}$ & & & -2.1828 & 0.0466 \\
$X_{2} X_{5}$ & -2.8776 & 0.0122 & & \\
$X_{2} X_{6}$ & & & & \\
$X_{3} X_{4}$ & 3.3560 & 0.0047 & & \\
$X_{3} X_{5}$ & 2.9570 & 0.0104 & & \\
$X_{3} X_{6}$ & 2.4350 & 0.0289 & & \\
$X_{5} X_{6}$ & 2.4276 & 0.0293 & & \\
$X_{1}{ }^{2}$ & -10.0325 & $8.97 E-8$ & 6.7638 & $9.11 E-6$ \\
$X_{5}{ }^{2}$ & 2.1956 & 0.0455 & & \\
\hline
\end{tabular}

${ }^{*}$ Only parameters having $P$ value of less than 0.05 are included in the table. Note. Values of high statistical significance $(P<0.01)$ are bold.

\section{Conclusions}

Response surface models have been generated using LHS design and have been shown to have good fitness. Parametric behaviour affecting neck moments during side impact crash affecting restrained child, which is previously unavailable, is captured. The singular and cross interactive parameter sensitivity for neck moments in a 3-year-old child involved in realistic intrusive side impact speed of $32.2 \mathrm{~km} / \mathrm{h}$ is studied and acceptable values of the $t$ statistic and its significance $P$ are obtained and reported.

The number of significant parameters affecting the neck moment is shown to be the largest for wide impact angles $\left(\phi \geq 60^{\circ}\right)$ and the PDOF angle $X_{1}$ is largely revealed to be the most sensitive parameter. An ideal safe range for low NM has been established to be within $\phi$ angles $45^{\circ}$ and $65^{\circ}$. It is reported that $X_{1}$ has an increasing effect on $\mathrm{NM}$ at wide impact angles but, for narrow impact angles, the opposite holds true. The other parameters are generally found to be moderately significant only for wide PDOF impact angles. It has been shown that the harness friction coefficient $\left(X_{4}\right)$ has relatively very little effect on NM.

The nature of all parameters effect on the NM (of weather increasing or decreasing) is shown to be highly dependent on the impact angle range. Thus, it is understood that oblique 
side impact with intrusion affects the neck moment very differently compared to purely lateral crash.

\section{Conflict of Interests}

The authors declare that there is no conflict of interests regarding the publication of this paper.

\section{References}

[1] National highway Traffic Safety Administration (NHTSA), Traffic Safety Facts 2011 Data (DOT HS 811 767), U.S. Department of Transportation, 2013, http://www-nrd.nhtsa .dot.gov/pubs/811729.pdf.

[2] Statistics Canada 2005, "Major Causes of Death, Government of Canada," 2007, http://142.206.72.67/02 /02b /02b_003_e.htm.

[3] A. Carlsson, J. Strandoth, K. Bohman et al., "Review of child occupant fatalities in Sweden during six decades," in Proceedings of the International Research Council on Biomechanics of Injury Conference (IRCOBI '13), Gothenburg, Sweden, 2013.

[4] A. Kirk, P. Lesire, and S. Schick, "Child car passenger fatalitiesEuropean Figures and In-Depth Study," in Proceedings of the 9th International Conference on Protection of Children in Cars, Munich, Germany, 2011.

[5] M. Starnes and A. Eigen, "Fatalities and Injuries to 0-8 years old passenger vehicle occupants based on impact attributes," Tech. Rep. DOT HS 809 410, NHTSA, Washington, DC, USA, 2002.

[6] L. Decina and K. Knoebel, "Patterns of misuses of child safety seats," Tech. Rep. DOT HS 808 440, National Highway Traffic Safety Administration, Washington, DC, USA, 1996.

[7] T. Kapoor, W. Altenhof, A. Howard, J. Rasico, and F. Zhu, "Methods to mitigate injury to toddlers in near-side impact crashes," Accident Analysis and Prevention, vol. 40, no. 6, pp. 1880-1892, 2008.

[8] M. Andersson, K. B. Arbogast, B. Pipkorn, and P. Lövsund, "Characteristics of crashes involving injured children in side impacts," International Journal of Crashworthiness, vol. 16, no. 4, pp. 365-373, 2011.

[9] A. Howard, L. Rothman, A. M. McKeag et al., "Children in side-impact motor vehicle crashes: seating positions and injury mechanisms," Journal of Trauma, vol. 56, no. 6, pp. 1276-1285, 2004.

[10] K. B. Arbogast, Y. Ghati, R. A. Menon, S. Tylko, N. Tamborra, and R. M. Morgan, "Field investigation of child restraints in side impact crashes," Traffic Injury Prevention, vol. 6, no. 4, pp. 351360, 2005.

[11] K. Arbogast, I. Chen, D. Durbin, and F. Winston, "Child restraints in side impacts," in Proceedings of the International CoNMerence on the Biokinetics of Impact, Graz, Austria, 2004.

[12] K. Weber, "Crash protection for child passengers: a review of best practice," UMTRI Research Review, vol. 31, no. 3, pp. 1-28, 2000.

[13] J. Heiko, G. Barley, S. Carine et al., "Review of the development of the ISO side impact test procedure for child restraint systems," in Proceedings of the 20th Enhanced Safety of Vehicles Conference (ESV '07), Lyon, France, 2007.

[14] NHTSA Vehicle Crash Test Database, Test no 4585, 2007, http://www-nrd.nhtsa.dot.gov/database/aspx/biodb/querytesttable.aspx.

[15] T. Kapoor, W. Altenhof, A. Snowdon et al., "A numerical investigation into the effect of CRS misuse on the injury potential of children in frontal and side impact crashes," Accident Analysis and Prevention, vol. 43, no. 4, pp. 1438-1450, 2011.

[16] Q. Wang, T. Kapoor, M. Tot, W. Altenhof, and A. Howard, "Child restraint seat design considerations to mitigate injuries to three-year-old children in side impact crashes," International Journal of Crashworthiness, vol. 12, no. 6, pp. 629-644, 2007.

[17] TNO Automotive, MADYMO Manual Version 7.4.1, Delft, The Netherlands, 2013.

[18] ECE R95, "Reg 95 Uniform provisions concerning the approval of vehicles with regard to the protection of the occupants in the event of a lateral collision, United Nations Economic Commission for Europe," http://www.unece.org/ fileadmin/DAM/trans/main/wp29/wp29regs/r095a4cle.pdf.

[19] S. Shasthri, Q. Shah, V. Kausalyah, M. Idres, K. Abdullah, and S. V. Wong, "Lateral side impact crash simulation of restrained 3 year old child," in Proceedings of the 2nd International Conference on Recent Advances in Automotive Engineering \& Mobility Research, December 2013.

[20] FMVSS Federal Motor Vehicle Safety Standards, Standard No 213, Child Restraint Systems, US Department of Transportation, 2013, http://www.fmcsa.dot.gov/rules-regulations/ administration/fmcsr/fmcsrruletext.aspx? reg=571.213.

[21] NHTSA, "Notice of proposed rulemaking (NPRM), 67 FR 21806, docket no 11707 FMVSS 213," 2014, http://www.gpo .gov/fdsys/pkg/FR-2014-06-04/html/2014-12899.htm. 

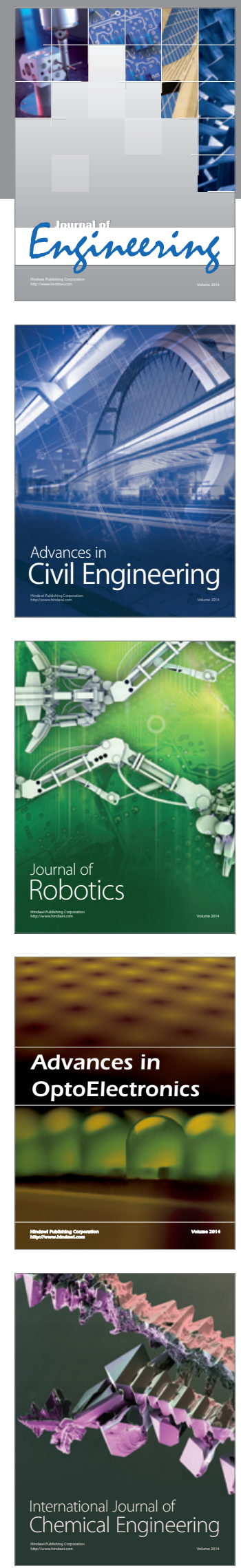

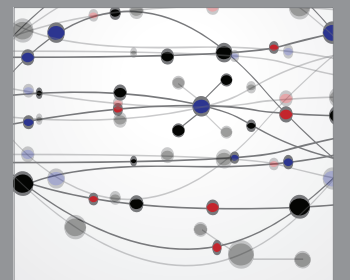

The Scientific World Journal
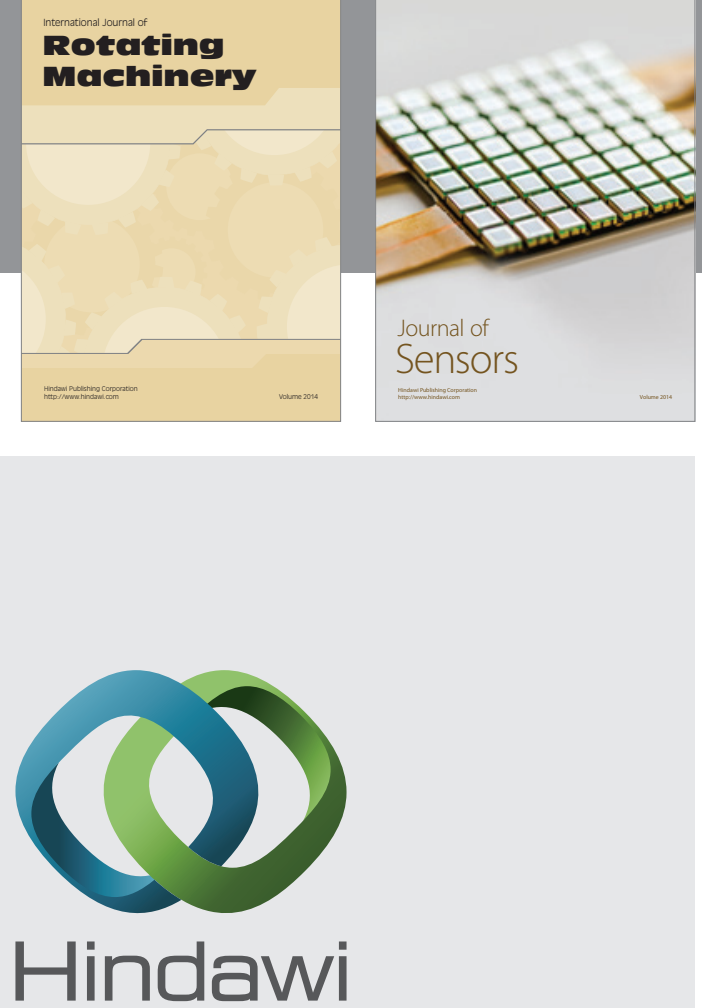

Submit your manuscripts at http://www.hindawi.com
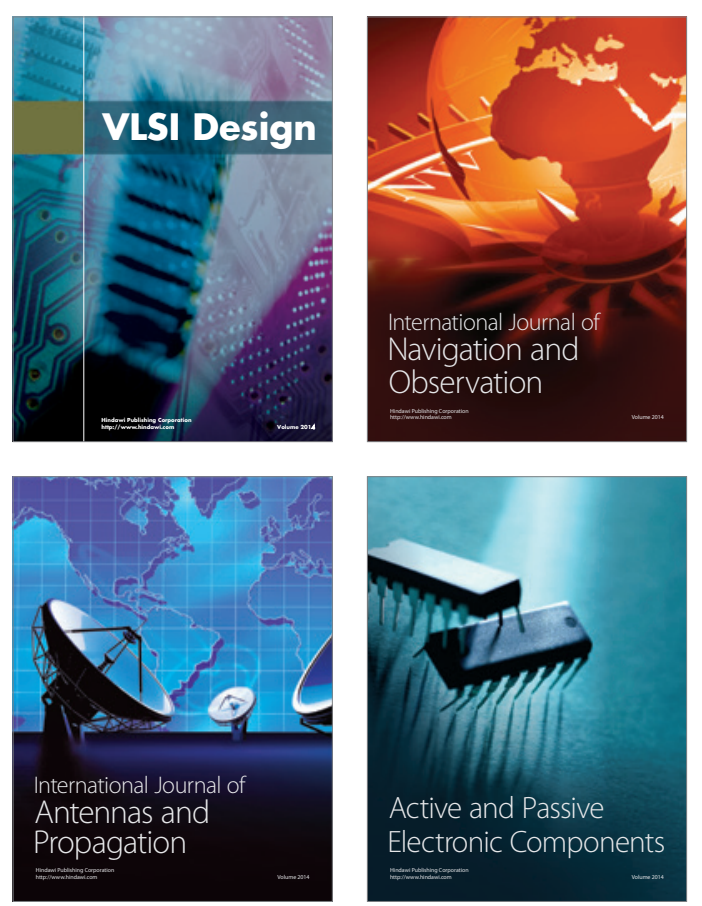
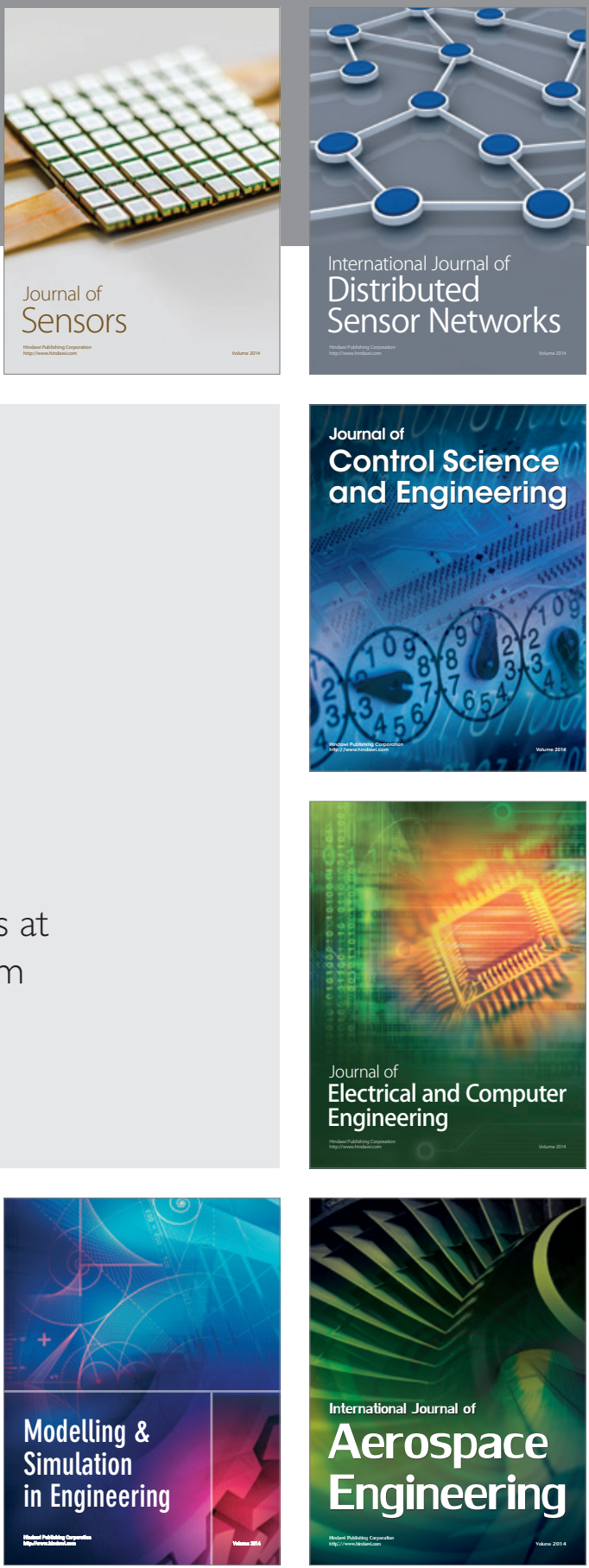

Journal of

Control Science

and Engineering
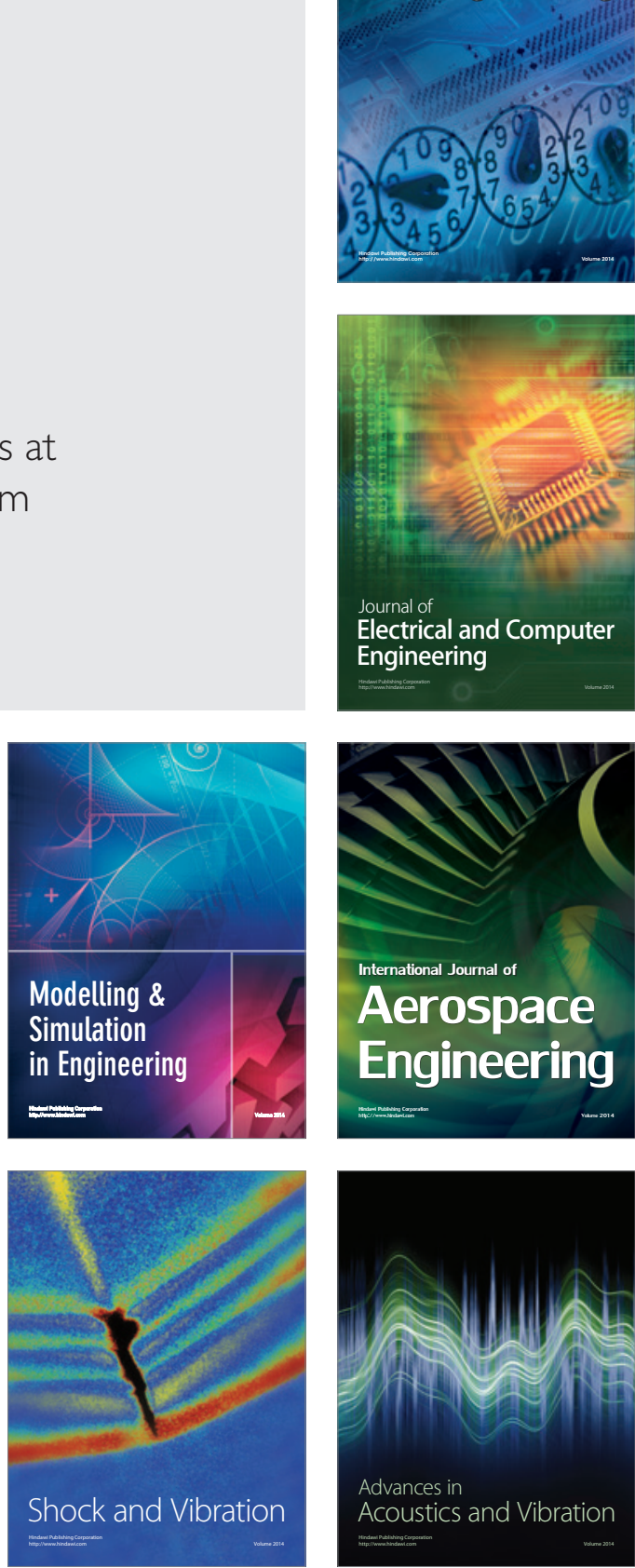